\title{
MORFOLOGIA DELAPARATO BUCAL EN Hypostomus aculeus e Hypostomus pyrinensi (PISCES, SILURIFORMES, LORICARIIDAE)
}

\author{
Ruth Dueñas Peralta ${ }^{1}$
}

\begin{abstract}
RESUMEN
Se describió aquí las características morfológicas del aparato bucal de dos especies simpátridas y sintópicas de «carachamas» de la familia Loricaridae (Hypostomus aculeus e H. pyrinensi), del rio Huallaga, Tingo Maria, Huanuco. Por la forma bucal en diamante y sus dientes robustos y fuertes en $H$. aculeus le permite raspar en el substrato y se alimentaría de partículas grandes. Sin embargo, en $H$. pyrinensi se alimentaría de partículas muy finas y por succión ya que sus dientes son pequeños y débiles.
\end{abstract}

Palabras Claves: Aparato bucal, Loricaridae, Hypostomus aculeus e Hypostomus pyrinensi.

\section{SUMMARY}

Buccal morphology of Carachaza of the Loricaridae Family (Hypostomus aculeus e H. pyrinensi) from rio Huallaga, Tingo Maria, Huanuco were described here. By the buccal form in diamond and its robust and strong teeth in H. aculeus allows it to scrape in the substratum and it would be fed on great particles. Nevertheless, in $H$. pyrinensi would be fed on very fine particles and by suction because their teeth are small and weak.

Key words: Buccal apparatus, Loricaridae, Hypostomus aculeus e Hypostomus pyrinensi.

\section{INTRODUCCION}

Alexander (1965), Schaefer \& Lauder (1986) y Geerinckx et al. (2007) mensionaron que los peces de la familia Loricariidae son muy especiales porque pueden replegar su labio inferior contra de la cara ventral de la cabeza, de tal forma, que los dientes son dirigidos hacia el sustrato y así poder alimentarse, principalmente de algas y detritus.

Esta actividad pone al descubierto una variación morfológica bucal. Asi, Delariva \& Agostinho (2001), analizaron la cavidad oral y dientes de seis especies de la familia Loricariidae (Rhinelepis aspera, Megalancistrus aculeatus, Hypostomus regani, $H$. microstomus, $H$. ternetzi e $H$. margaritifer) observando la cavidad oral en $R$. aspera servía para ingerir finos sedimentos asociados a sus dientes pequeños y cónicos, sin embargo, $M$. aculeatus, $H$. microstomus e $H$. margaritifer, tienen dientes largos y espatulados con el arco dental en forma de rombo, el cual, le permite raspar superficies duras. En $H$. regani e $H$. ternetzi tienen labios y arcos dentarios en forma de semi-luna con dientes delgados apropiados para el raspado de las partículas más pequeñas que se encuentran en las superficies. La variabilidad de formas de dientes en Hypostominae y Ancistrinae se ha ido observando desde el desarrollo ontogénico, lo que permite agruparlos en especies hermanas (Muller \& Weber 1992).

En el presente trabajo se describió las características morfología del aparato bucal de dos especies simpátridas y sintópicas de Loricariidae (Hypostomus aculeus e Hypostomus pyrinensi), del río Huallaga, Tingo Maria, Huanuco. El material estuvo depositado en el Museo de Historia Natural de la Universidad Ricardo Palma - MHNURP: Hypostomus aculeus (MHNURP 75-84) e Hypostomus pyrinensi (MHNURP 68-70). El análisis del aparato bucal de cada especie se hizo bajo la técnica de coloración Azul Alcian - Rojo de Alizarina (Dingerkus \& Uhler, 1977) para tener un mejor contraste.

\section{Morfología de Hypostomus aculeus}

Posición y forma de la boca

\footnotetext{
${ }^{1}$ Museo de Historia Natural - Universidad Ricardo Palma. Av. Benavides 5440, Las Gardenias, Lima 33, Perú. rth727@hotmail.com
} 
Presenta la boca en posición ventral, labios en forma de ventosa. Labio superior menos desarrollado que el inferior y presenta una barbilla a cada lado; ambos labios son carnosos y posee papilas adhesivas, con el cual puede adherirse al substrato; boca en forma de embudo. (Fig. 1A).

\section{Dientes}

Las mandíbulas forman un ángulo $43^{\circ}$. Cada mandíbula presenta dos filas de dientes dispuestos en forma de « $\mathrm{V}$ » (Fig. 1A), cada fila posee 10 dientes, no se observaron diferencias en la forma de los dientes, a excepción de los dientes laterales que son más pequeños. Los dientes maxilares son ordenados en una fila formando una estructura muy parecida a un rastrillo, los dientes son robustos, unicuspides (Fig. 1B). Las coronas de los dientes son curvados y en forma de cuchara (Fig. 1C).

\section{Morfología de Hypostomus pyrinensi \\ Posición y forma de la boca}

Presenta la boca en posición ventral, labios en forma de ventosa. Labio superior menos desarrollado que el inferior y presenta una barbilla a cada lado; ambos labios son carnosos y posee papilas adhesivas, con el cual puede adherirse al substrato; boca en forma de embudo. (Fig. 2A).

Dientes

Cada mandíbula presenta dos filas de dientes, cada fila posee aproximadamente 46 dientes, no se observaron diferencias en la forma y tamaño de los dientes. Los dientes maxilares de Hypostomus pyrinensi, son ordenados en una fila formando una estructura muy parecida a un rastrillo. Las coronas de los diente son recta, más delgada y corta y tiene forma de espátula (Fig. 2B). Dientes delgados, la corona presenta una cúspide principal grande, al lado una bicúspide lateral pequeña (Fig. 2C).

\section{DISCUSION}

Ambas morfologías, boca y dientes, facilitan la adquisición de alimento; estas estructuras determinan la forma en la cual la especie toma el alimento. El desarrollo de las valvas orales y el ancho de la cavidad de la boca de Hypostomus pyrinensi, facilita la ingesta de finas partículas de sedimento haciendo uso de la succión. $H$. pyrinensi probablemente no raspa arduamente el substrato, porque tiene dientes en forma de espátula, rectos, pequeños y algo débiles, mientras que Hypostomus aculeus, presenta las valvas orales y la cavidad de la boca en forma de diamante probablemente para la ingesta de partículas no muy finas haciendo uso de los dientes, los cuales son robustos y duros; presentan la corona del diente en forma de cuchara lo cual le facilita raspar en el substrato duro.

\section{LITERATURA CITADA}

ANDRADE, P. M. \& BRAGA, F. M. 2005. Diet and feeding of fish from Grande river, located bellow the volta Grande Reservoir, MG-SP. Brazilian Journal of Biology, 65: 377-385,

CASATTI L.; ROCHA F. C. \& D. C. PEREIRA. 2005. Habitat use by two species of Hypostomus (Pisces, Loricariidae) in Southeastern Brazilian streams. Biota Neotropica, 5: 1-9.

DELARIVA R. L. \& A. A. AGOSTINHO. 2001. Relationship between morphology and diets of six neotropical loricariids. Journal of Fish Biology 58: 832-847.

DINGERKUS G. \& L. UHLER. 1977. Enzyme clearing of alcian blue stained whole small vertebrates for demonstration of cartilage. Stain Technology. 52: 229-232

GEERINCKX, T.; DE POORTER J. \& D. ADRIAENS. 2007. Moorphology and Development of Teeth and Epidermal Brushes in Loricariid Catfishes. Journal of Morphology. 268: 805-814.

MONTEiro, A. C.; CASTELO, C. W. \& V. GUIMARÃES. 2005. Estudo da dieta natural de peixes no reservatório de Ribeirão das Lajes, Rio de Janeiro, Brasil. Acta de la Sciedade de Biologia 27: 355-364,

MULLER, S. \& C. WEBER. 1992, Les dents de sous-families Hypostominae et Ancistrinae (Pises, Siluriformes, Loricariidae) et leer valeur taxonomique. Rev Suisse Zool 99: 747-754.

\section{FIGURAS}

Fig. 1.- A: Vista del disco bucal de Hypostomus aculeus, que presenta 2 pares filas de dientes dispuestas en forma de «V», con aproximadamente 10 dientes en cada fila. B: La corona del diente presenta forma de cuchara, todos los dientes presentan la misma forma, a excepción de los laterales que son más pequeños. C: Esquema de la corona del diente de Hypostomus aculeus. Barra $=4 \mathrm{~mm}$.

Fig. 2.- A: Vista del disco bucal de Hypostomus pyrinensi, que presenta 2 filas de dientes por mandíbula, con aproximadamente 46 dientes cada fila. B: La corona del diente presenta forma de espátula, con una cúspide grande al lado de una bicúspide lateral pequeña; todos los dientes presentan la misma forma y tamaño. C: Esquema de la corona del diente de Hypostomus pyrinensi. Barra $=7 \mathrm{~mm}$. 


\section{FIGURA 1}
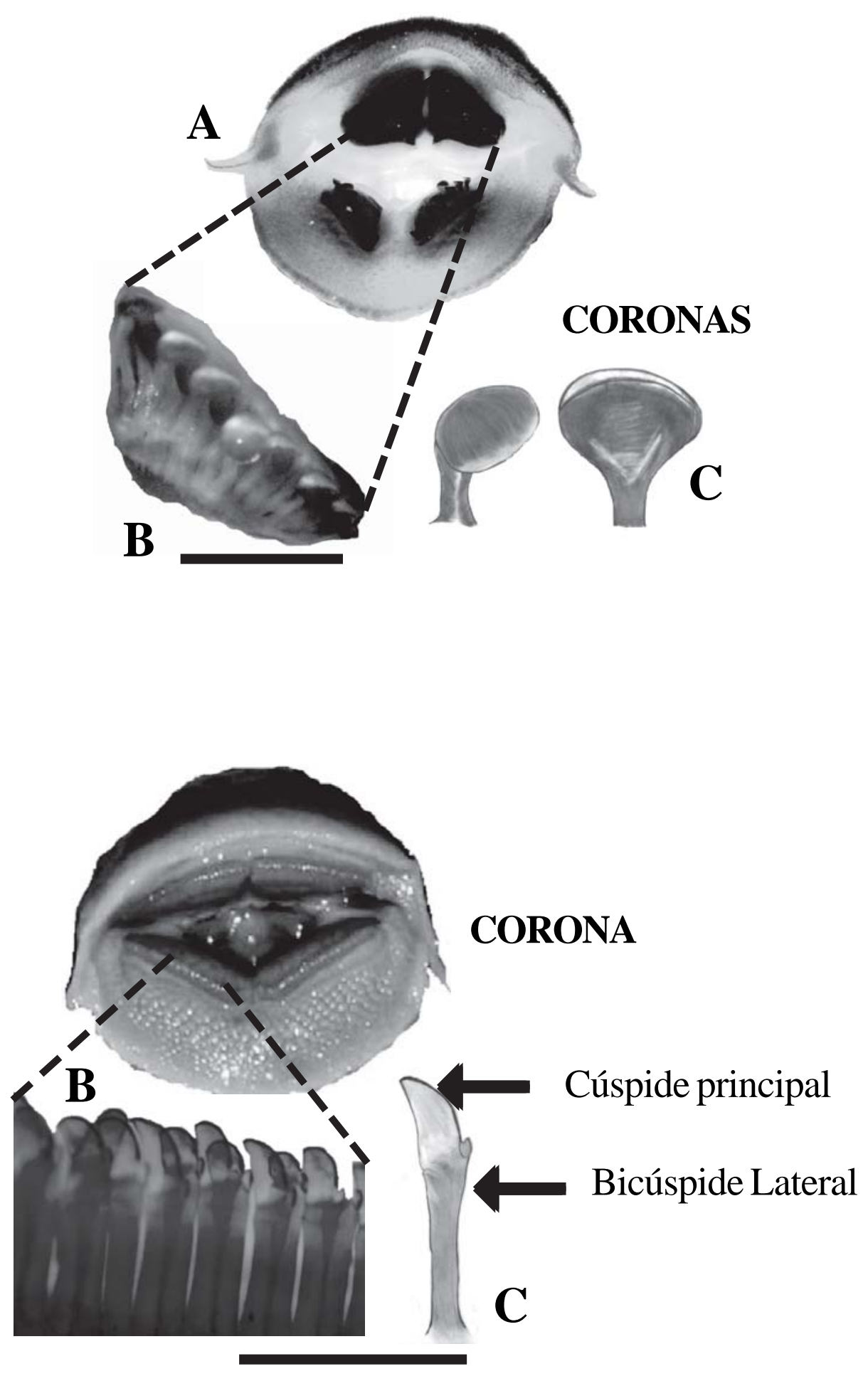